\title{
Putative HIV and SIV G-Quadruplex Sequences in Coding and Noncoding Regions Can Form G-Quadruplexes
}

\author{
Petra Krafčíková, Erika Demkovičová, Andrea Halaganová, and Viktor Víglaský \\ Department of Biochemistry, Institute of Chemistry, Faculty of Sciences, P. J. Safarik University, 04001 Kosice, Slovakia \\ Correspondence should be addressed to Viktor Víglaský; viktor.viglasky@upjs.sk
}

Received 30 July 2017; Revised 26 September 2017; Accepted 18 October 2017; Published 31 December 2017

Academic Editor: Shozeb Haider

Copyright (c) 2017 Petra Krafćíková et al. This is an open access article distributed under the Creative Commons Attribution License, which permits unrestricted use, distribution, and reproduction in any medium, provided the original work is properly cited.

\begin{abstract}
The HIV virus is one of the most studied viruses in the world. This is especially true in terms of gene sequencing, and to date more than 9 thousand genomic sequences of HIV isolates have been sequenced and analyzed. In this study, a series of DNA sequences, which have the potential to form G-quadruplex structures, is analyzed. Several such sequences were found in various coding and noncoding virus domains, including the U3 LTR, tat, rev, env, and vpx regions. Interestingly, a homological sequence to the already well-known HIV integrase aptamer was identified in the minus-strand. The sequences derived from original isolates were analyzed using standard spectral and electrophoretic methods. In addition, a recently developed methodology is applied which uses induced circular dichroism spectral profiles of G-quadruplex-ligand (Thiazole Orange) complexes to determine if G-rich sequences can adopt G-quadruplex structure. Targeting the G-quadruplexes or peptide domains corresponding to the G-rich coding sequence in HIV offers researchers attractive therapeutic targets which would be of particular use in the development of novel antiviral therapies. The analysis of G-rich regions can provide researchers with a path to find specific targets which could be of interest for specific types of virus.
\end{abstract}

\section{Introduction}

The human immunodeficiency virus (HIV) is an RNA retrovirus in the Retroviridae family which causes HIV infection and over time can lead to acquired immunodeficiency syndrome (AIDS). The virus belongs to the single-stranded positive-sense RNA Lentivirus genus and is formed from two molecules of genomic RNA that are converted into double-stranded DNA by the viral reverse transcriptase. The resulting viral DNA is then inserted into the cellular DNA by the HIV integrase. Once integrated, transcription from the proviral promoter at the $5^{\prime}$ long terminal repeat (LTR) generates mRNAs which code viral proteins and genomic RNA. The integrated provirus may become latent and the infected host cell can remain undetected by the immune system. To date, more than nine thousand HIV-1, SIV, and HIV-2 subtypes have been completely or partially sequenced. The genomic HIV contains regions rich in G-residues which show a marked tendency to adopt G-quadruplex structures, and a number of studies published in recent years have revealed the biological significance of G-quadruplexes in
HIVs [1-7]. G-quadruplexes have long been seen as a highly promising target for the development of new anticancer therapies $[8,9]$, but recent work has also suggested the possibility of adopting a similar strategy for the development of antiviral therapies. Formation of G-quadruplex is usually linked to moderate DNA transcription [10,11]. Research devoted to G-quadruplexes has so far been limited to the field of viral genomes, despite the advantages of their small size and often naturally occurring double-stranded circular (episomal) form. One important study found that the Gquadruplex Epstein-Barr virus could disrupt the interaction of EBV nuclear antigen 1 with RNA. The linking regions of EBNA1 LR1 and LR2 were revealed to have a strong preference for G-quadruplex RNA and it was revealed that G-quadruplex RNA-interacting drugs block the functions of EBNA1 that are critical for viral DNA replication and episome maintenance $[12,13]$.

Recently it was confirmed that consensus sequences forming stable G-quadruplex structures are responsible for RNA replication and inhibition of protein translation of hepatitis $\mathrm{C}$ virus [14]. 
Our recently published results have also highlighted the significance of some G-rich regions in regulating areas with the ability to form stable G-quadruplexes in papilloma viruses [15].

G-quadruplex structures also seem to be critical for HIV-1 infectivity and could represent novel targets for antiviral drug development. For example, it is known that mutations disrupting G-quadruplex formation can enhance HIV promoter activity in cells and that treatment with G-quadruplex ligands decreases promoter activity and displays antiviral effects [6]. The $\mathrm{U} 3$ region contains a $\mathrm{G}$-rich sequence $\sim 80$ nucleotides upstream from the transcription-starting site (TSS) and close to the TATA box. This sequence overlaps three SP1 binding sites which play a crucial role in the initiation of transcription $[1,4]$. Recent research has confirmed the interaction between the Sp1 protein and a fragment of the HIV-1 promoter sequence folded into a G4 [16], and the effect of point mutations which disrupt the G-quadruplexes formed in the promoter has been analyzed [6].

Retroviral RNAs are now known to dimerize via G-rich regions in the cytoplasm of infected cells allowing two copies of the genome which is encapsidated in the newly produced virion [17]. The mechanisms which drive RNA dimerization play a role during the strand transfers which may be partially responsible for the viral variability through the production of recombinant molecules $[18,19]$.

G-rich sequences can form bimolecular G-quadruplex structures in the gag region of the HIV-1 genome, in close proximity to the dimer initiation site (DIS) [16, 20-22]. It has recently been shown that the recombination in the $\mathrm{U} 3$ domain is cation-dependent and is significantly lower in the presence of lithium ions, ions which are known to destabilize G-quadruplexes [23].

G-quadruplexes derived from the sequence of the negative regulatory factor (Nef) of HIV-1 were recently analyzed in vitro [5]. Nef G-quadruplexes repress the Nef expression and this finally results in a decrease in viral replication. Thus, targeting the G-quadruplexes located in the Nef coding sequence could lead to further attractive therapeutic opportunities.

Therefore, the main goal of this study is to scrutinize HIV provirus genomes in an attempt to find G-rich regions which may be prone to forming G-quadruplex motifs. Several tools and strategies are available to predict G-quadruplex propensity from some sequences, but there are disadvantages and limitations associated with each algorithm [24-27]. Within the last ten years, it has become generally accepted that stable G-quadruplexes are mainly formed in G-rich regions consisting of four G-runs that contain two or more continuous guanosine residues $\left(\mathrm{G}_{2-4}\right)$ interrupted by 1-7 nucleotides $\left(\mathrm{G}_{2-4} \mathrm{~N}_{i} \mathrm{G}_{2-4} \mathrm{~N}_{j} \mathrm{G}_{2-4} \mathrm{~N}_{k} \mathrm{G}_{2-4}\right)$ [28, 29]. The inner core of G-quadruplexes is based on the stacking of two or more G-tetrads, although some sequences, such as the VEGF aptamer, do not form in this way; this aptamer contains a loop which lacks any nucleotide residue [30]. Initially, our study was aimed at focusing on putative sequences $\left(\mathrm{G}_{3} \mathrm{~N}_{i} \mathrm{G}_{3} \mathrm{~N}_{j} \mathrm{G}_{3} \mathrm{~N}_{k} \mathrm{G}_{3}\right)$ which are able to form G-quadruplexes consisting of three G-quartets connected with loops shorter than 5 residues, but no sequences matching this criterion were found in the various HIV/SIV proviral genomic sequences which we prescreened randomly. Therefore, a different condition for finding G-quadruplex forming sequences in HIV genomes was applied: the desired sequences must consist of three G-runs $\left(\mathrm{G}_{n}, n \geq 3\right)$ and one dinucleotide island GG; see more details in Material and Methods. In fact, the existence of stable G-quadruplexes containing only 3 continuous G-runs has recently been confirmed, and this sequential motif can form so-called bulged G-quadruplexes [31]. Many such sequences have been found in various regions of HIV genomes, and those which are analyzed in this study are summarized in Figure 1. The formation and structure of G-quadruplexes of each oligonucleotide were verified using UV and CD spectroscopy and electrophoretic separation in the presence of either sodium or potassium ions. In order to exclude the false confirmation of G-quadruplex formation on the base of the CD spectra profiles alone, CD melting curves were also determined because the stability of all known G-quadruplexes is significantly higher in the presence of potassium than in the presence of sodium ions.

\section{Material and Methods}

All chemicals and reagents were obtained from commercial sources. DNA oligomers were obtained from Metabion, Germany (Figure 1). PAGE purified DNA was dissolved in double distilled water prior to use. Thiazole Orange was purchased form Sigma-Aldrich (cat. number 390062). Singlestrand concentrations were determined precisely by measuring absorbance $(\sim 260 \mathrm{~nm})$ at $95^{\circ} \mathrm{C}$ using molar extinction coefficients [15]. DNA concentration was determined using UV measurements carried out on a Jasco J-810 spectropolarimeter (Easton, MD, USA). Cells with optical path lengths of $10 \mathrm{~mm}$ were used, and the temperature of the cell holder was controlled with an external circulating water bath.

2.1. G-Quadruplex Searching Criteria. The search criteria for G-quadruplex forming sequences were restricted to sequences which possessed three continuous G-runs containing at least three neighboring Gs and one G-run containing only two neighboring Gs. We aimed to identify sequences with 1-4 nucleotides occurring between two continuous Gruns and with fewer than 9 nucleobases between G-runs in total; thus, the total required number of Gs was set at a minimum of 12 . Initially, the reading frame of DNA was adjusted to 20 nucleotides (Figure 2 ).

The sequences fulfilling these criteria were considered as putative G-quadruplex forming sequences. If an additional G-run was located in close proximity (i.e., less than 3 nucleotides) to the putative sequence, it was also judged to be suitable for inclusion. In principle, we applied criteria similar to those utilized by QGRS mapper and the more comprehensive mining tool QuadBase2, a program which predicts G-quadruplex forming G-rich sequences (QGRS) in nucleotide sequences [27, 32]. The scores of G-quadruplex putative sequences found in HIV genomes were also analyzed using G4Hunter strategy (Figure 1) [25]. It is important to note that QGRS mapper and G4Hunter strategies can miss many sequences which were found by our access. 


\begin{tabular}{|c|c|c|c|c|c|c|c|}
\hline Number & Name & nt & $\varepsilon^{\S}$ & Sequence $5^{\prime} \rightarrow 3^{\prime}$ & $\begin{array}{l}\text { Subtype } \\
\text { region }\end{array}$ & Genbank ID & $\begin{array}{l}\mathrm{G}^{2} \mathrm{H}^{£} \\
\text { Hits } \\
{ }^{\circledR}\end{array}$ \\
\hline (1) & H2-U22 & 27 & 312.0 & TGGGGGGAGGACATGGGCCGGGAGGGT & \multirow{3}{*}{$\begin{array}{l}\text { HIV-2 } \\
\text { Vpx }\end{array}$} & U22047.1 & $\begin{array}{c}1.85 \\
\bullet\end{array}$ \\
\hline (2) & H2-M15 & 26 & 306.0 & TGGGGAGGGGACATGGGCCAGGAGGG & & M15390.1 $\$$ & 1.88 \\
\hline (3) & $\mathrm{H} 2-\mathrm{U} 38$ & 23 & 267.0 & TGGGGGGAGGACATGGGCCGGGA & & U38293.1 $\$$ & $\begin{array}{l}1.78 \\
\bullet\end{array}$ \\
\hline (4) & H1-JX & 26 & 302.0 & 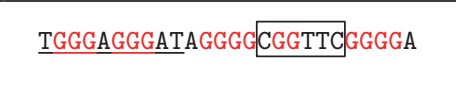 & \multirow{3}{*}{$\begin{array}{l}\text { HIV-1 } \\
\text { LTR (Sp1) }\end{array}$} & JX245015.1 & $\begin{array}{c}2.00 \\
\bullet\end{array}$ \\
\hline (5) & H1-JX1 & 26 & 300.0 & TGGGAGGGACAGGGGCGGTTCGGGA & & $J X 245014.1^{\$}$ & $\begin{array}{l}1.96 \\
\bullet\end{array}$ \\
\hline (6) & H1-L20 & 27 & 317.0 & TGGGAGGGATAAGGGGCGGTTCGGGGA & & L20571.1 & $\begin{array}{c}1.63 \\
\bullet\end{array}$ \\
\hline (7) & $\mathrm{H} 2-\mathrm{U} 38 \mathrm{~B}$ & 20 & 250.0 & AGGGAGGGACATGGGAGGAG & \multirow{3}{*}{$\begin{array}{c}\text { HIV2 } \\
\text { LTR (Sp1) }\end{array}$} & $\mathrm{U} 38293.1^{\$}$ & $\begin{array}{l}1.55 \\
. .\end{array}$ \\
\hline (8) & H2-J0 & 21 & 254.0 & $\underline{\text { GGGGAGGGACATGGGAGGAGC }}$ & & J04498.1 $1^{\$}$ & $\begin{array}{l}1.76 \\
\bullet \bullet\end{array}$ \\
\hline (9) & $\mathrm{H} 2-\mathrm{M} 15 \mathrm{~B}$ & 30 & 362.0 & AGGGAGGGACATGGGAGGAGCTGGTGGGGA & & M15390.1 $\$$ & $\begin{array}{c}1.63 \\
. \bullet\end{array}$ \\
\hline (10) & S-M30 & 25 & 280.0 & GGGCGGGTCATGGG CGGTACGGGGA & \multirow[t]{2}{*}{$\begin{array}{l}\text { HIV-1, SIV } \\
\text { LTR (Sp1) }\end{array}$} & M30931.1 $\$$ & 1.72 \\
\hline (11) & S-JX & 22 & 242.0 & CGGGGCGGGGTTGGGGAGTGGC & & $J X 112863.1^{\$}$ & $\begin{array}{c}2.27 \\
\bullet \bullet\end{array}$ \\
\hline (12) & H1-JN & 21 & 234.0 & TGGGCGGGACTGGGGAGTGGC & \multirow{3}{*}{$\begin{array}{c}\text { HIV1 } \\
\text { LTR (Sp1) }\end{array}$} & JN882653.1 & $\begin{array}{l}1.71 \\
\cdots . .\end{array}$ \\
\hline (13) & H1-K02 & 22 & 242 & GTGGCCTGGGCGGGACTGGGGA & & K02083.1 & 1.50 \\
\hline (14) & H1-M27 & 22 & 239.0 & GTGGCCTGGGCGGGACTTGGGA & & M27323.1 $\$$ & $\begin{array}{c}1.23 \\
. \bullet\end{array}$ \\
\hline (15) & H1-K03 & 18 & 202.0 & CGGGGTTGGGAGGTGGGT & $\begin{array}{l}\text { HIV1, SIV } \\
\text { Tat, Rev, Env }\end{array}$ & K03455.1 ${ }^{\$}$ & $\begin{array}{c}2.05 \\
\ldots\end{array}$ \\
\hline (16) & H1-JN-A & 22 & 257.0 & AGGGACTGAGGCTGGGGTGGGA & $\begin{array}{c}\text { HIV1 } \\
\text { Rev, Env }\end{array}$ & JN882653.1 $\$$ & $\begin{array}{c}1.68 \\
\bullet \bullet \bullet\end{array}$ \\
\hline
\end{tabular}

$\$$ Occurrence in other organisms containing at least one point-mutation. ${ }^{\$}$ Millimolar extinction coefficient at $264 \mathrm{~nm}$

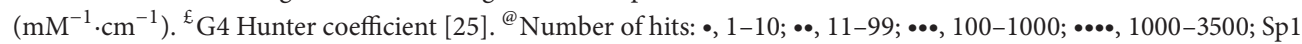
consensus sequence $5^{\prime}$-(G/T)GGGCGG(G/A)(G/A)(C/T)-3' is underlined; G-runs are highlighted by red color. The rectangular selection represents the supposed loops of G-quadruplexes consisting of four Gn-runs $(n \geq 3)$.

FIGURE 1: DNA oligonucleotides used in this study originating from HIVs and SIVs.

The randomly selected complete genomic sequences of 20 different HIV-1, 5 HIV-2, and 5 SIV viruses were analyzed, thereby identifying the sequences listed in Figure 1. The name of the oligonucleotide was derived from the type of virus and the first letters of ID; the abbreviations H1-, H2-, and Srepresent HIV-1, HIV-2, and SIV, respectively. Bioinformatic analysis was then performed by analyzing the occurrence of each sequence in other genomes using the Basic Local Alignment Search Tool (BLAST), a tool which can identify regions of local similarity between sequences [33]. The sequences summarized in Figure 1 were compared with the complete and partial genome sequences of all known HIVs available in the NCBI Gene database. Oligonucleotides numbers 1, $2,4,5,6,9$, and 10 at the $3^{\prime}$-termini contain an additional proximal $\mathrm{G}_{3}$-run, and our criteria allow this to be included in the final sequence. However, the sequences marked by rectangles in such cases can represent the supposed loops of "standard" G-quadruplexes consisting of four $\mathrm{G}_{n}$-runs $(n \geq 3)$. However, the sequences of oligonucleotides used in experimental measurements are too short for relevant sequence alignment, as this approach is primarily used to examine sequences located in long terminal repeat regions (LTRs). Therefore, the wider regions were also used for bioinformatics analyses by adjusting the frame which is restricted by the NF- $\kappa-\mathrm{B}$ and TATA boxes for sequences located in LTRs. A similar methodology was also used for the translation products of the sequences located in coding regions.

2.2. Circular Dichroism Spectroscopy. CD spectra were recorded on a Jasco J-810 spectropolarimeter equipped with a PTC-423L temperature controller using a quartz cell of $1 \mathrm{~mm}$ optical path length in a reaction volume of $150 \mu \mathrm{l}$. All other parameters and conditions were the same as those which were described previously $[14,33]$. The modified Britton-Robinson buffer (mBR) was used in all spectral analyses where TRIS was used instead of potassium/sodium hydroxide $(25 \mathrm{mM}$ phosphoric acid, $25 \mathrm{mM}$ boric acid, and $25 \mathrm{mM}$ acetic acid) and supplemented by either $50 \mathrm{mM}$ potassium chloride or 


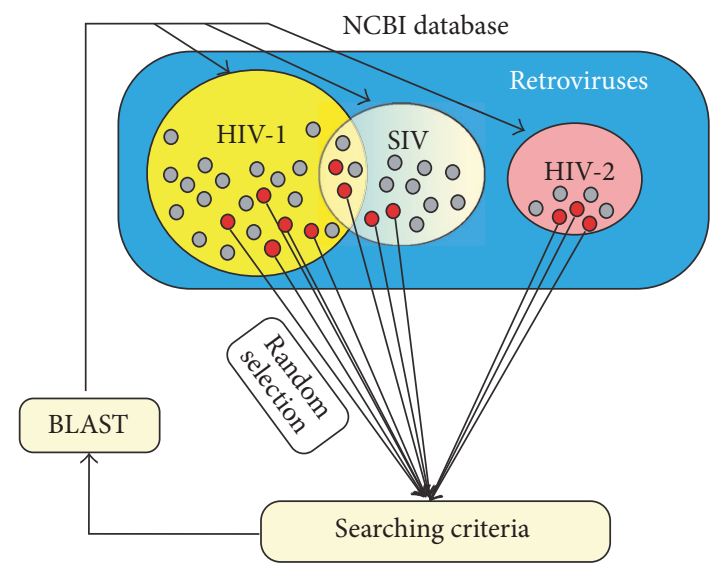

(a)

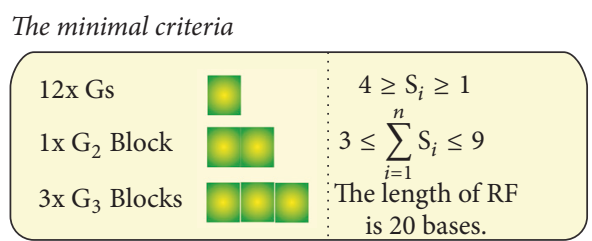

(b)

The specific criteria for G-runs $\left(\mathrm{G}_{N}, N>4\right)$

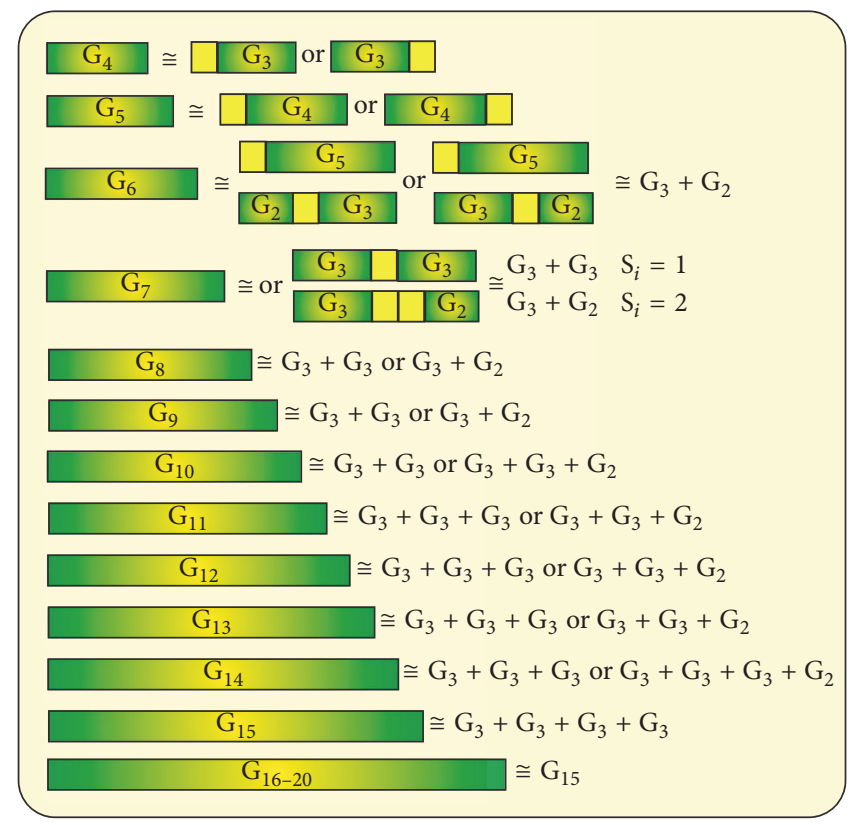

Guanosines in the loop

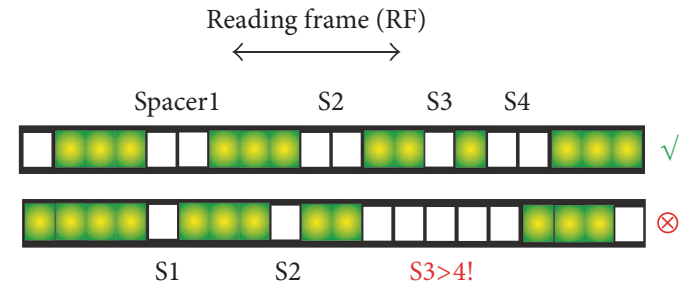

(d)

(c)

Sequence reading

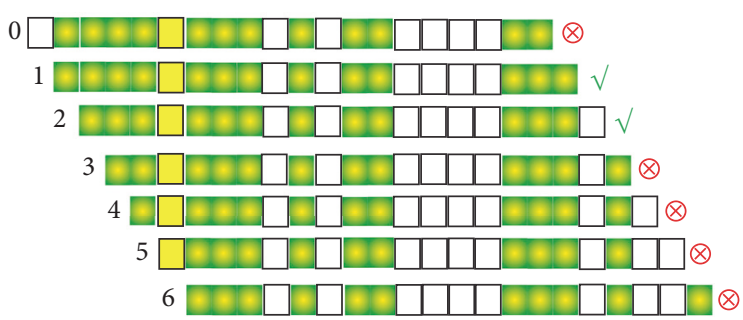

(e)

FIGURE 2: Strategy and searching criteria of putative G-quadruplex sequences. Randomly selected genomic sequences of HIV-1, HIV-2, and SIV from NCBI Gene database were analyzed (panel (a)). The criteria used to determine putative G-quadruplex sequences are listed in panel (b). $\sum S_{i}$ represents the total number of nucleotide residues between $G$-runs $\left(G_{3}\right.$ and $\left.G_{2}\right)$, and this value is restricted at the interval $\langle 3-9\rangle$. Specific criteria were applied in cases in which G-runs consisted of more than four Gs (c); for instance, $G_{7}$ is formed of either two $G_{3}$ islands interrupted with one G (yellow square) or one G3 and G2 connected with two "yellow" Gs. The occurrence of putative sequences was researched by BLAST in other viruses listed in the Gene database. Positive and negative examples of the search procedure are shown in panels (d) and (e). 

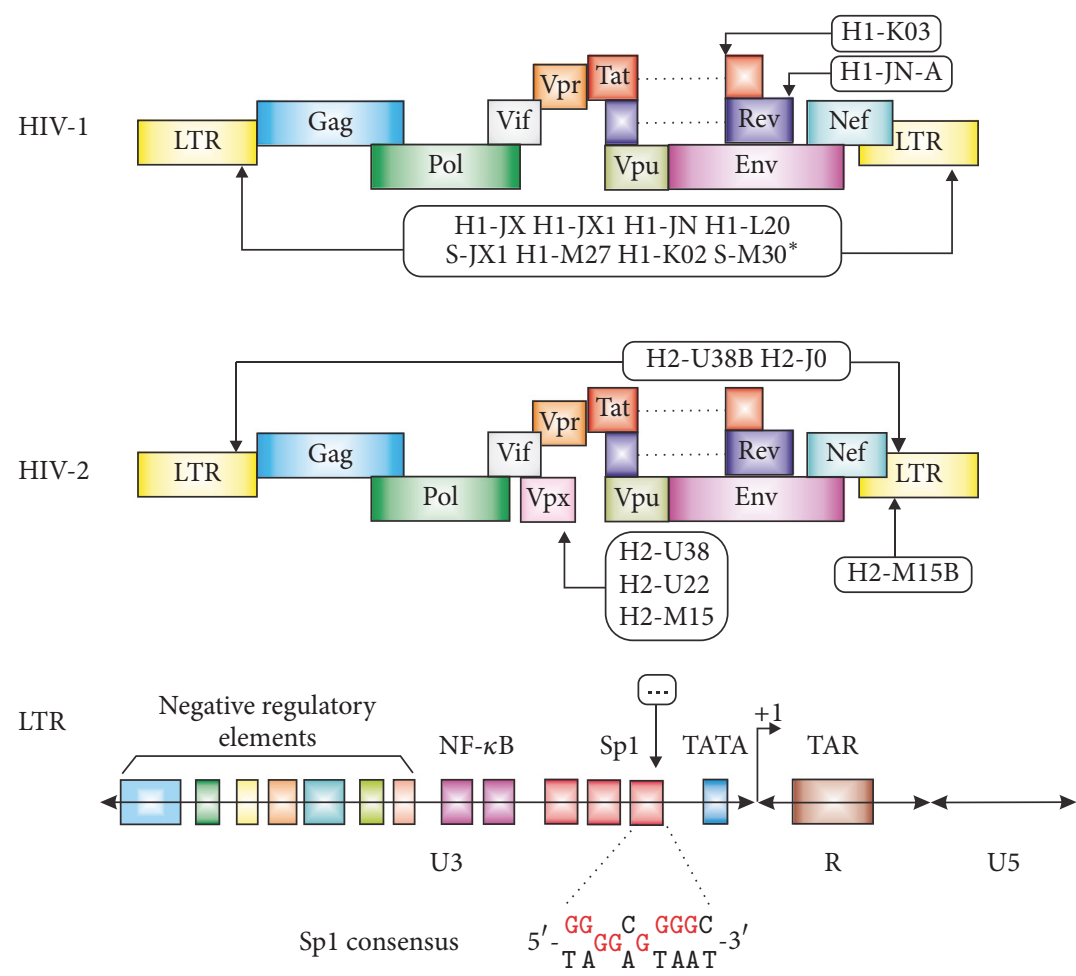

FIGURE 3: Schematic drawing of the HIV-1 and HIV-2 genome organizations and locations of studied sequence.

sodium chloride. $\mathrm{pH}$ was adjusted by TRIS to a final value of 7.0.

DNA titration was performed with increasing concentrations of Thiazole Orange (TO). TO was solubilized in DMSO to reach a final concentration of stock solution of $10 \mathrm{mM}$. The concentrations of DNA and TO in a $1 \mathrm{~mm}$ quartz cell were $30 \mu \mathrm{M}$ and $0-200 \mu \mathrm{M}$, respectively, and the increment of TO was $\sim 67 \mu \mathrm{M}$. Each sample was mixed vigorously for $3 \mathrm{~min}$ following the addition of TO; $\mathrm{CD} / \mathrm{UV}$ spectra were measured immediately.

2.3. CD Melting Curves. CD melting profiles were collected at $\sim 295$ and $\sim 265 \mathrm{~nm}$ as a function of temperature, using a procedure which has been published previously [33]. The temperature ranged from 0 to $100^{\circ} \mathrm{C}$, and the heating rate was $0.25^{\circ} \mathrm{C}$ per minute. The melting temperature $\left(T_{m}\right)$ was defined as the temperature of the midtransition point.

2.4. Thermal Difference Spectra. The conditions and parameters used in the examination of the thermal difference spectra were identical to those used in the CD spectroscopy assay. The spectra analysis performed in this study has been described in an earlier publication [34].

2.5. Electrophoresis. Native polyacrylamide gel electrophoresis (PAGE) was performed in a temperature controlled vertical electrophoretic apparatus (Z375039-1EA, SigmaAldrich, San Francisco, CA). Gel concentration was 12\% (19: 1 monomer to bis ratio, Applichem, Darmstadt). Approximately two micrograms of DNA was loaded onto $14 \times 16 \times$ $0.1 \mathrm{~cm}$ gels. Prior to loading, each DNA sample was heated to $95^{\circ} \mathrm{C}$ for $5 \mathrm{~min}$ in an appropriate buffer and cooled to room temperature. Electrophoreses were performed at $20^{\circ} \mathrm{C}$ for 4 hours at $120 \mathrm{~V}\left(\sim 8 \mathrm{~V} \cdot \mathrm{cm}^{-1}\right)$. DNA oligomers were visualized with Stains-All immediately after electrophoresis, and the electrophoretic record was photographed on a white pad with a Nikon D3100 camera. The gel was also later stained by silver staining procedure in order to improve the sensitivity of the DNA visualization $[15,35]$.

\section{Results and Discussion}

3.1. Bioinformatic Analysis. Although many different HIV sequence comparisons have been performed to date, this study offers an alternative means of identifying putative G-quadruplex forming sequences. The search criteria were not restricted to the LTR regions of the proviral HIV genome, but were instead applied to the entire proviral HIV genome. In this overview, the occurrence of 16 selected oligonucleotide sequences within more than nine thousand previously sequenced HIV/SIV genomes was examined in an attempt to identify some general relationship between them. The sequence structure consisting of three G-runs containing at least three neighboring Gs and one G-run containing two Gs was found in HIV-1, HIV-2, and SIV provirus DNAs. These sequences and their sources are summarized in Figure 1. Some sequences were also found in other organisms, but some of these are obligatory, located only in an appropriate HIV genome (Figure 3).

3.1.1. The Vpx Region. The sequence H2-U22 was found only in one HIV-2 isolate in the terminal part of the vpx region (ID: 
U22047.1), but its derivatives containing 1-3 point mutations were found in an additional $9 \mathrm{HIV}-2$ isolates. H2-U38 is a truncated version of $\mathrm{H} 2-\mathrm{U} 22$, and this sequence was found again in the same region in an additional five HIV-2 genomic sequences (ID: M30502.1, U38293.1, M31113.1, U22047.1, and KU168289.1). The first 20 nucleotides of $\mathrm{H} 2-\mathrm{M} 15$ are identical to those of the H2-U22 and H2-U38 sequences, and this oligomeric sequence occurred very rarely in HIVs, being found in only 2 isolates of HIV-2 in vpx region (ID: X05291.1, M15390.1) and two derivatives containing 1-2 mutations. Interestingly, both sequence derivatives can also be found in other organisms. Considering the extreme rarity of these three sequences in HIV-2 genomes, their significance and biological role are questionable.

3.1.2. Env/Rev Region. The G-rich region located in the env gene of HIV-1 is also a promising potential source of G-quadruplex formations. The env and rev coding sequences overlap, but their reading frames are different. This region contains the H1-JN-A sequence which occurs in only $11 \mathrm{HIV}-1$ isolates, but a derivative in which the central guanosine is substituted for adenosine (AGGGACTGAGACTGGGGTGGGA) occurs in more than $1000 \mathrm{HIV}-1$ isolates. Interestingly, our results confirm that the formation of G-quadruplex is not affected and this sequence adopts preferentially the dimer form (not shown). There is some analogy here between the abasic site in the second G-run and the $\mathrm{G}$ for $\mathrm{A}$ substitution which has been the subject of recent studies by two different groups $[36,37]$. The abasic site and the $\mathrm{G}$ for A substitution decrease the thermodynamic stability of such derivative sequences. Therefore, this substitution might not be sufficient to prevent such sequences from forming G-quadruplex motifs. It should be possible to verify the influence of a $G$ for A substitution in the second G-run on a series of oligonucleotides. These results lead us to form the hypothesis that the formation of G-quadruplexes, as with the formation of other secondary motifs, could lead to a pausing effect on the DNA replication, transcription, or translation of the env and rev regions [38-40].

A number of different research projects have attempted to identify conserved structural motifs in highly variable viruses which can be used as specific targets for the development of efficient antiviral therapies. Interestingly, H1-JN-A sequence encodes the oligopeptides Gly-Leu-Arg-Leu-Gly-Trp-Glu and Gly-Thr-Glu-Ala/Thr-Gly-Val-Gly which are integral parts of Env and Rev proteins, respectively. These oligopeptide motifs are highly abundant in HIV-1 proteins and were found in more than 1140 coding sequences of Env and Rev.

3.1.3. The Minus-Strand. All of the sequences described thus far are found in the plus-DNA/RNA strand. However, the sequence $5^{\prime}$-ACCCACCTCCCAACCCCG- $3^{\prime}$ is typically located in the plus-strand of HIV-1 at the beginning of the second exon of tat/rev and env genes. This motif is complementary to the sequence $5^{\prime}$-d(CGGGGTTGGGAGGTGGGT)- $3^{\prime}$ in the minus-strand and, interestingly, is very similar to the well-known HIV-93del aptamer d(GGGGTGGGAGGAGGGT), which forms very stable interlocked dimeric G-quadruplex [41]; the two sequences differ in two bases. Additionally, 98 known HIV-1 isolates differ only in one extra thymine compound between the first two G-runs, for example, isolate KU168259.1 in Gene bank. The H1-K03 sequence is located in 1160 various HIV-1 isolates.

Although the homology of $\mathrm{H} 1-\mathrm{K} 03$ and aptamer sequences is undoubtedly interesting, we are unable to offer a convincing explanation for the phenomenon. Nevertheless, this is the first reported case of a natural coding sequence being homological to an aptamer which was originally developed against the protein produced by the same organism. Is this merely a coincidence or is it an exception? However, if the sequence was located in the coding strand, it would be possible to elucidate an explanation or a convincing theory about the biological role of the sequence.

3.1.4. LTR Regions. In recent years, a wide range of research and publications has focused on the study of G-rich sequences in LTR. In principle, the results of our research into U3 LTR sequences fully corroborate the earlier findings of other authors [2-4, 6, 7]. The H1-L20, H1-JX, and H1-JX1 sequences are very similar; indeed, H1-JX and H1-JX1 differ only in one central nucleobase. These sequences were found in HIV-1 genomes in LTR Sp1 region. Their occurrences are 8 and 9 hits for H1-JX and H1-JX1, respectively. Their derivatives were found in more than 30 various HIV-1 isolates. H1-L20 was found in only 5 isolates, although variants containing 1-2 point mutations were located in an additional 28 isolates. The formula implying all possible variants of HIV isolates which overlay H1-L20, H1-JX, and H1-JX1 sequences is

\section{5' -TGGGAGGRAYRDKGGGYGGDHSDGGGA-3',}

where the following nomenclature of wobbles in DNA nucleobases is used: $R=(A$ or $G), B=(C$ or $G$ or $T), Y=(C$ or $T)$, $\mathrm{D}=(\mathrm{A}$ or $\mathrm{G}$ or $\mathrm{T}), \mathrm{S}=(\mathrm{G}$ or $\mathrm{C}), \mathrm{H}=(\mathrm{A}$ or $\mathrm{C}$ or $\mathrm{T}), \mathrm{W}=(\mathrm{A}$ or $\mathrm{T}), \mathrm{V}=(\mathrm{A}$ or $\mathrm{C}$ or $\mathrm{G}), \mathrm{K}=(\mathrm{G}$ or $\mathrm{T}), \mathrm{M}=(\mathrm{A}$ or $\mathrm{C})$, and $\mathrm{N}$ can be any base.

The H1-JN sequence was found in a significantly higher number of HIV-1 variants, 3181 hits in HIV-1 genomic sequences and only one in the SIV isolate. This sequence was not found to occur in HIV-2 and other organisms. Recent studies have identified and described the structure of HIV1 sequence LTR-IV: d(CTGGGCGGGACTGGGGAGTGGT) and their derivatives [42], and the underlined nucleotides of this sequence are homological to H1-JN sequence. The parallel G-quadruplex containing the bulge was confirmed by NMR analysis (PDB ID: 2N4Y).

H1-K02 and H1-M27 sequences are highly homological. These sequences partially overlap with H1-JN; their occurrence in HIV-1 genome was again found to be very high and is identified in more than 1700 various isolates in the NCBI database. The first guanosine is highly conservative in both sequences. This guanosine could be essential for the formation of G-tetrads and may also contribute to the stability of G-quadruplexes exhibiting bulge features. The large size of the statistical set would suggest the likelihood of higher numbers of nucleobase variations, and this was confirmed by the BLAST analysis of the region occurring between NF- $\kappa$-B and TATA boxes of KJ849802.1, in which 


\begin{tabular}{|c|c|c|c|c|c|c|c|c|}
\hline D & $\mathrm{B} * \mathrm{D} \mathrm{R} * \mathrm{Y} * \mathrm{H}^{*} \mathrm{KR} \mathrm{WYM} \mathrm{W}$ & $\mathrm{V} \mathrm{K}^{*} * * * * * * \mathrm{R} \mathrm{Y}^{*} \mathrm{Y} *$ & {[} & & & & & \\
\hline KJ8 & G G G G A G G T G T G G G - C C - & $-\underline{\mathrm{T}} \underline{\mathrm{G}} \underline{\mathrm{G}} \underline{\mathrm{C}} \underline{\mathrm{G}} \underline{\mathrm{G}} \underline{\mathrm{G}} \underline{\mathrm{A}} \underline{\mathrm{C}} \underline{\mathrm{T}}-\mathrm{G}$ & G G & & 1 & & & \\
\hline trata & A G G G A G G C G T - G G - C C - & $-\underline{\mathrm{T}} \underline{\mathrm{G}} \underline{\mathrm{G}} \underline{\mathrm{G}} \underline{\mathrm{C}} \underline{\mathrm{G}} \underline{\mathrm{G}} \underline{\mathrm{G}} \underline{I}$ & & & & & $C$ & \\
\hline te & G G C G T-G G-C C - & $\underline{\underline{G}} \underline{\mathrm{C}} \underline{\mathrm{G}} \underline{\mathrm{G}} \underline{\mathrm{G}} \underline{\mathrm{A}} \underline{\mathrm{C}} \underline{\mathrm{T}} \mathrm{T} \mathrm{G}$ & $G$ u & & & T G G & $\mathrm{C}$ & \\
\hline 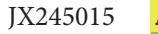 & 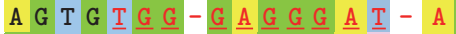 & A G G G G C - G G & $G G G$ & & & I G G & C & H1-JX \\
\hline 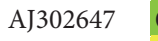 & $\underline{\mathrm{G}}-\underline{\mathrm{G}} \underline{\mathrm{A}} \underline{\mathrm{G}} \underline{\mathrm{G}} \underline{\mathrm{G}} \underline{\mathrm{A}} \underline{\mathrm{C}}-\mathrm{A}$ & A G G G G C - G G $-\mathrm{T}$. & & & & T G G & & \\
\hline $\mathrm{L} 20$ & $-\underline{\mathrm{A}} \underline{\mathrm{G}} \underline{\mathrm{G}} \underline{\mathrm{G}} \underline{\mathrm{A}} \underline{\mathrm{T}} \mathrm{A} A$ & A G G G G C - G G - T T C G & G G G & & & & & $\mathrm{H}$ \\
\hline & G G G G A G G T G T-G G-T C - & $\underline{T} \underline{T}-G$ & G G G & & & T G & & \\
\hline( & G G G G G A G - G C G T A A C C - & $-\underline{\mathrm{G}} \underline{\mathrm{G}} \underline{\mathrm{G}} \underline{\mathrm{C}} \underline{\mathrm{G}} \underline{\mathrm{G}} \underline{\mathrm{G}} \underline{\mathrm{G}} \underline{\mathrm{T}} \underline{\mathrm{T}}-\mathrm{G}$ & & & & & & $S$ \\
\hline 1309 & A G G G $-\cdots$ C G G G T C A T & $\begin{array}{c}\Gamma \mathrm{G} \mathrm{G} \mathrm{G-}-\mathrm{C}-\mathrm{G} \mathrm{G}-\mathrm{T} \text { A C G } \\
S p 1-I I\end{array}$ & & & & & & S-M30 \\
\hline
\end{tabular}

Possible gaps are marked with blue letters or symbols. The red letters represent the sequences used in this study; Sp1 consensus sequences are underlined.

FIGURE 4: Sequence alignment of LTR regions containing the sequence listed in Figure 1. Possible gaps are marked with blue letters or symbols. The red letters represent the sequences used in this study. Spl consensus sequences are underlined.

H1-JN was found to occur in 1061 various isolates. All possible variants express the formula

\section{$5^{\prime}$-N-RDDVNHDVGSHGRRRHNNRRGADKSVB-3'.}

The number of sequenced HIV-2 genomes was markedly smaller in comparison to that of HIV-1 and this inevitably resulted in a smaller statistical set. The sequence H2-U38B is a truncated version of $\mathrm{H} 2-\mathrm{M} 15 \mathrm{~B}$; with the exception of the terminal $5^{\prime}$-adenosine of $\mathrm{H} 2$-J0, the two sequences are a perfect overlap. Their occurrence in different isolates was not as frequent as H1-JN, possibly due to the smaller number of sequenced HIV-2 genomes; all the identified sequences occurred in the LTR of HIV-2 and not in HIV-1. The truncated H2-U38 and H2-J0 derivatives were not only limited to humans, but also found in many other organisms such as Ovis canadensis, Macaca fascicularis, Mus musculus, Rattus norvegicus, Mesocricetus auratus, and Fundulus heteroclitus and pigs and plants such as Solanum lycopersicum and Oryza punctate. 145 different isolates of HIV-2 were found in the wider region determined with the NF- $\kappa$-B and TATA boxes. The formula including all possible variants is as follows:

$$
5^{\prime} \text {-DRRGWRRNRYYTRGRRRGDRYYRGKRRGGA-3'. }
$$

The total number of all known HIV-1 sequences is much higher than the number of sequenced SIV genomes, but although the S-JX sequence originally found in SIV occurred prevalently in HIV-1 isolates, this was not the case for SM30 sequence. Both S-JX and S-M30 sequences were also located in the LTR Sp1 region. S-M30 was found only in one SIV isolate, but its derivatives were found in an additional 6 SIV genomes and in other organisms including Pseudomonas, elephant endotheliotropic herpesvirus, Enterobacter cloacae, Streptomyces leeuwenhoekii, and Leptosphaeria maculans lepidii.

The sequence alignment of the region containing the sequences used in this study, located in LTR of HIV-1 and SIV, is summarized in Figure 4. The alignments of the wider region determined by NF- $\kappa-\mathrm{B}$ and TATA boxes are shown in the Supporting Information (Table S1).

The formula including all possible variants is as follows:

$$
5^{\prime} \text {-NDRGGRHGGGRRYYDRGGAGTGG-3'. }
$$

The models describing the formation of four G-quadruplexes formed in the LTR region have been described in a recent study $[1,6,7]$. The structure of one of these, an antiparallel Gquadruplex structure composed of only two tetrads, was also confirmed using NMR [4]. These four topologies are mutually exclusive because the G-runs associated with the formation of a single G-quadruplex are overlaid with others, thereby preventing the formation of any of the three alternative conformations. This sequence of four G-runs or more arranged in tandem is not uncommon in viral genomes, and similar regions consisting of 5-7 G-runs have also been found in human papillomaviruses [15]. Thus, the equilibrium between these forms may play a role in regulating promoter activity in viruses.

Targeting G-quadruplexes including the possible variations located in the LTR coding sequence of HIVs can therefore offer an attractive therapeutic opportunity for the development of highly efficient inhibitors of processes depending on the secondary motifs in this regulating region.

3.2. $C D$ Measurements. Another aim of this study was to confirm the ability of the studied oligonucleotides to form stable G-quadruplexes. In order to ascertain this, a series of experiments using circular dichroism analysis was performed (Figure 5). DNA oligonucleotides were analyzed in a buffer supplemented with $50 \mathrm{mM}$ of potassium and sodium ions. All the studied oligonucleotides showed signatures which are typical for the formation of G-quadruplex structures in the presence of $50 \mathrm{mM} \mathrm{KCl}$; positive $\mathrm{CD}$ peaks were recorded at $\sim 265 \mathrm{~nm}$ and/or $295 \mathrm{~nm}$. The comparison of relative molar intensity of CD peaks with human telomeric repeats sequence at 265 or $295 \mathrm{~nm}$ shows that the sequence which folds into G-quadruplex can consist of three tetrads [34]. All CD spectra and $\mathrm{CD}$ melting profiles obtained in the presence of sodium and potassium are summarized in Supporting Figure S1.

3.3. Electrophoretic Analysis. Information about the molecularity and the presence of multimeric conformers of Gquadruplexes can be obtained by examining samples using electrophoretic separation [43]. Electrophoreses were performed in the presence of $50 \mathrm{mM} \mathrm{KCl}$ and $\mathrm{NaCl}$ at $20^{\circ} \mathrm{C}$ 

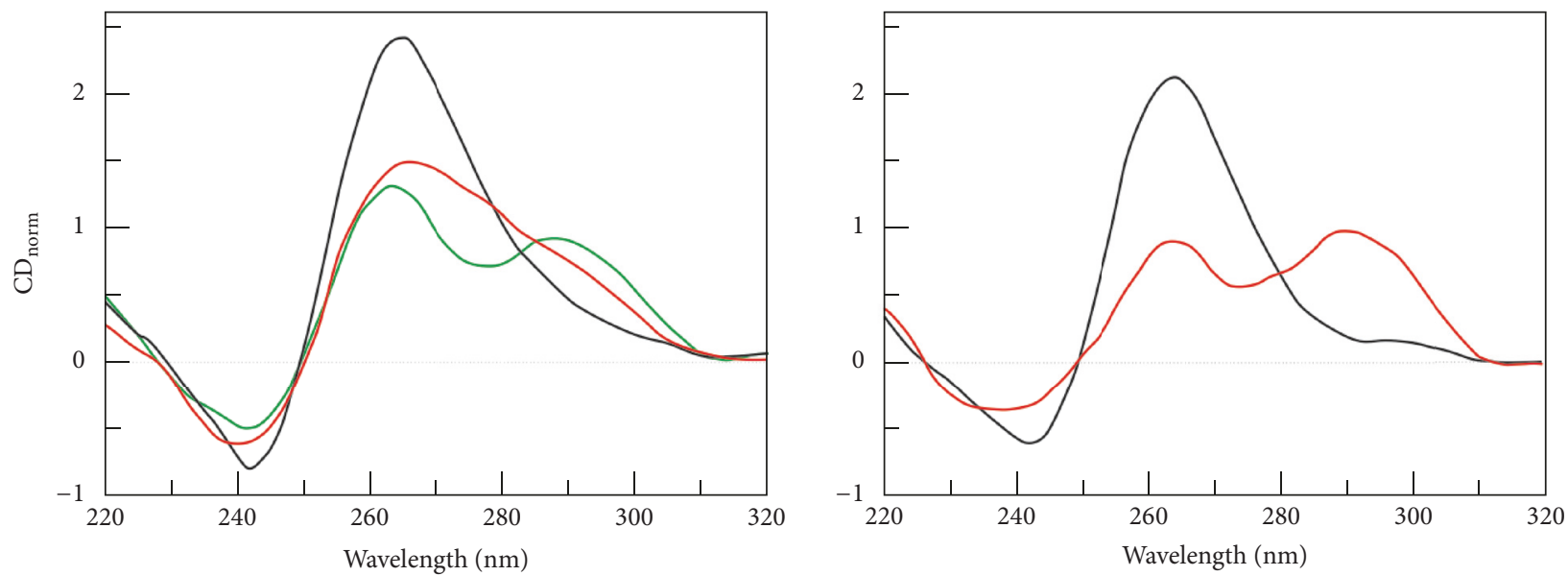

- $\mathrm{H} 2-\mathrm{U} 38$

$-\mathrm{H} 2-\mathrm{U} 22$

- H2-M15

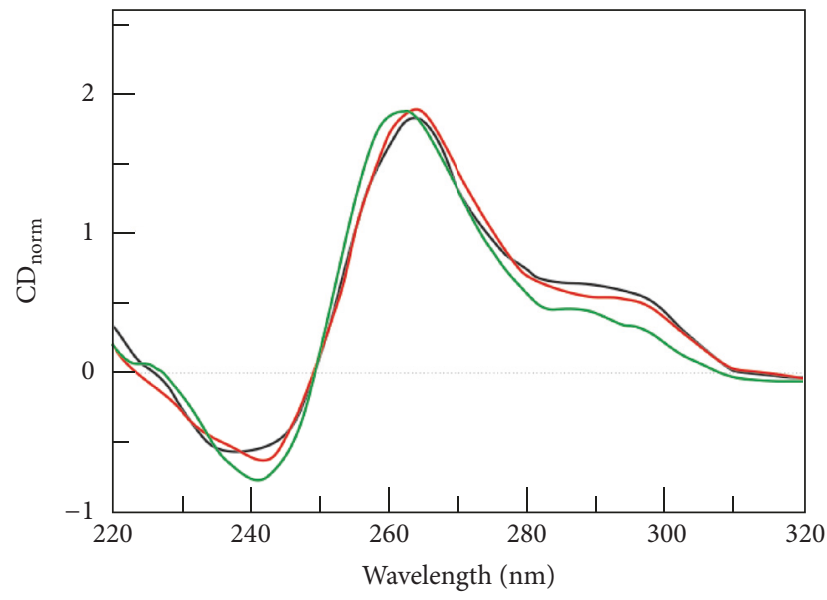

- H1-K03

- H1-JN-A

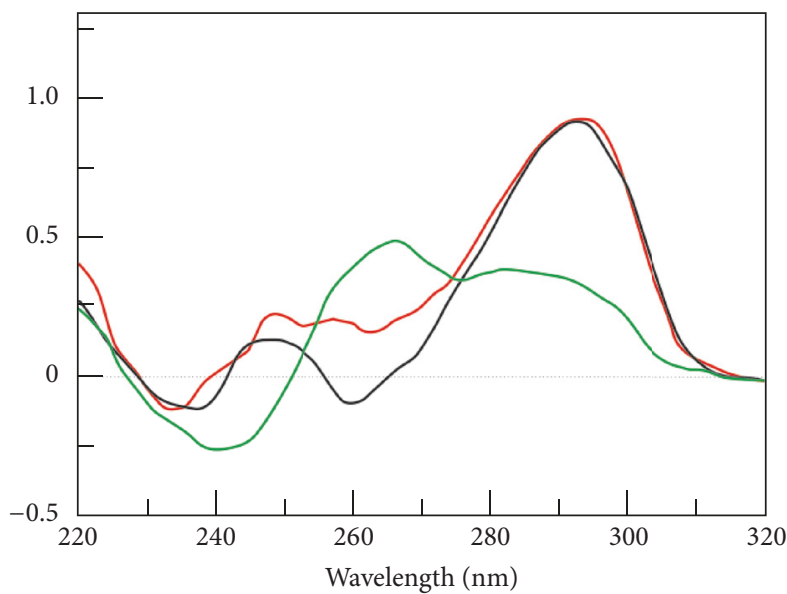

- H1-JX

- H1-M27

- H1-JX1

- H1-L20

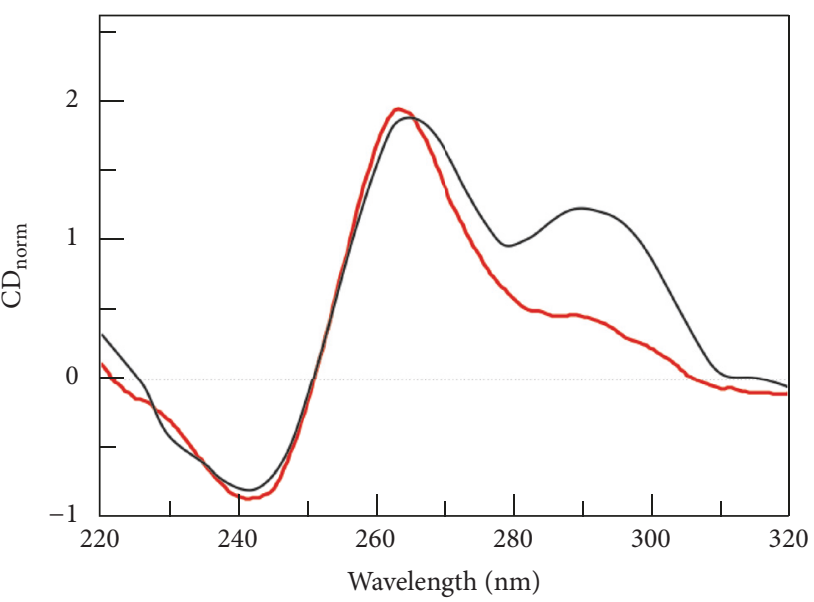

- $\mathrm{H} 1-\mathrm{K} 02$

- H1-JN

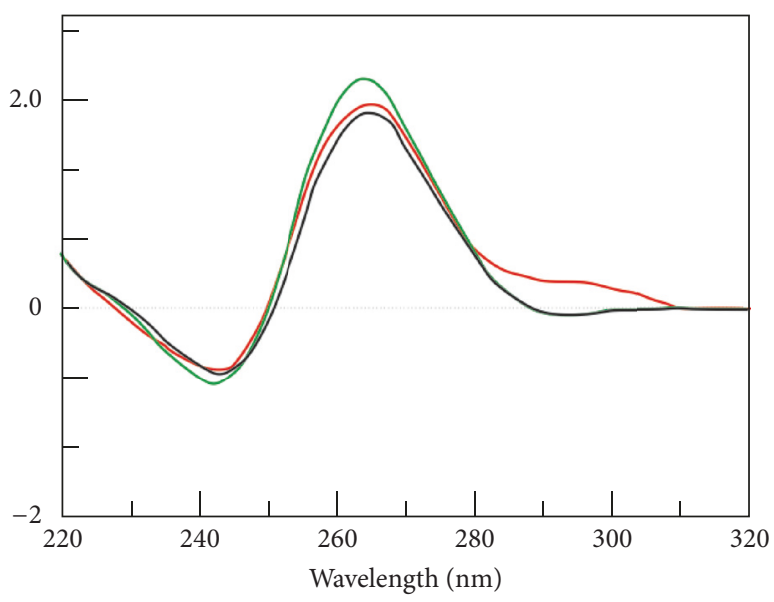

S-JX
$-\mathrm{S}-\mathrm{M} 30$

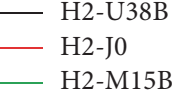

FIGURE 5: CD spectra of HIV oligomers in modified $25 \mathrm{mM} \mathrm{mBR}$ buffer (pH 7.0) in the presence of $50 \mathrm{mM} \mathrm{KCl}$. The corresponding UV, TDS, and CD melting curves obtained at 265 and $293 \mathrm{~nm}$ are shown in Supporting Figures S1 and S2. 


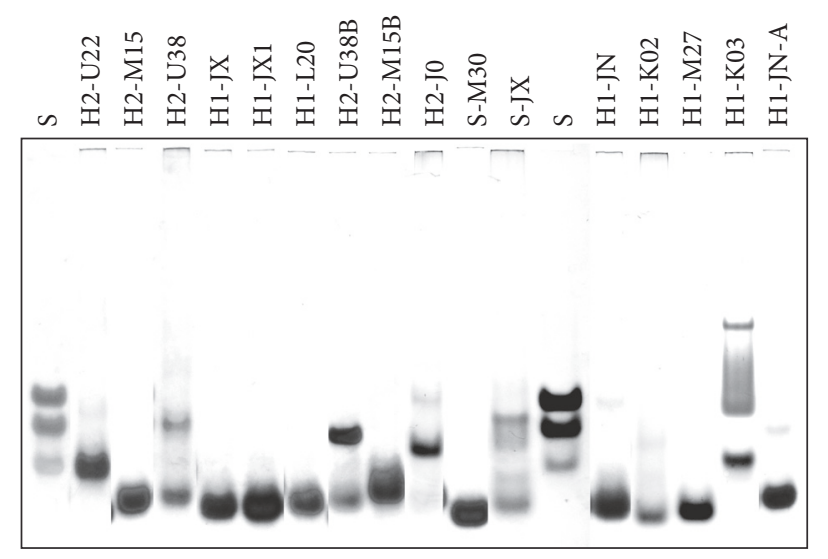

(a)

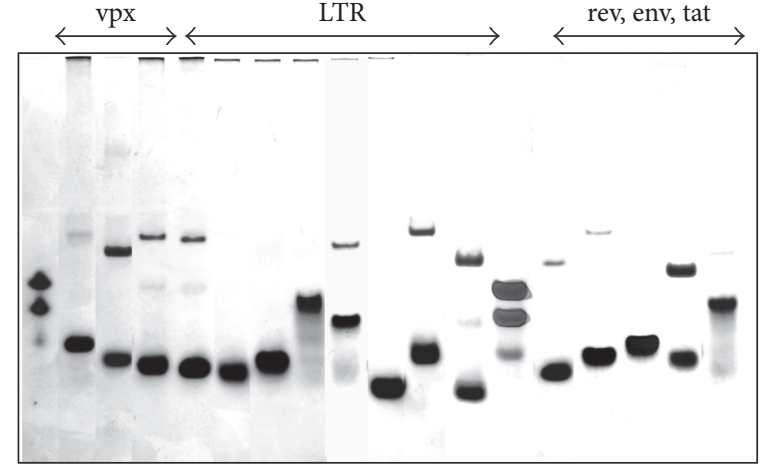

(b)

Figure 6: Molecular standard S, the mix of $\mathrm{d}(\mathrm{AC})_{9}, \mathrm{~d}(\mathrm{AC})_{14}$, and $\mathrm{d}(\mathrm{AC})_{18}$, was used. Electrophoretic separation was performed in a $14 \%$ polyacrylamide gel at $10^{\circ} \mathrm{C}$ in $25 \mathrm{mM}$ Britton-Robinson buffer (pH 7.0) and $50 \mathrm{mM} \mathrm{KCl}$ at $8^{\circ} \mathrm{C}$ in (a) and $50 \mathrm{mM} \mathrm{NaCl}$ in (b). Prior to being used, the DNA sample was heated in the same buffer for $5 \mathrm{~min}$ at $\sim 98^{\circ} \mathrm{C}$ and slowly cooled to room temperature within $30 \mathrm{~min}$.

TABLE 1: Melting temperatures and molecularities of the studied DNA oligonucleotides in the presence of $50 \mathrm{mM}$ sodium and potassium ions.

\begin{tabular}{|c|c|c|c|c|c|}
\hline & \multirow[b]{2}{*}{ Oligo. } & \multicolumn{2}{|c|}{ Potassium } & \multicolumn{2}{|c|}{ Sodium } \\
\hline & & Fold & $T_{m}\left[{ }^{\circ} \mathrm{C}\right]$ & Fold & $T_{m}\left[{ }^{\circ} \mathrm{C}\right]$ \\
\hline (1) & H2-U38 & M, D & $56.8^{p}$ & $M, D$ & $52.4^{\mathrm{p}}$ \\
\hline (2) & H2-U22 & $\mathrm{M}$ & $56.6^{\mathrm{p}}$ & $M \gg D$ & ND \\
\hline (3) & H2-M15 & $\mathrm{M}$ & $57.1^{\mathrm{a}, \mathrm{p}}$ & $\mathrm{M}, \mathrm{D}$ & $46.6^{\mathrm{p}}$ \\
\hline (4) & H1-JX & $\mathrm{M}$ & $57.5^{\mathrm{a}, \mathrm{p}}$ & $\mathrm{M}>\mathrm{D}$ & $30.3^{\mathrm{a}}, 52.5^{\mathrm{p}}$ \\
\hline (5) & H1-JX1 & $\mathrm{M}$ & $61.6^{\mathrm{a}, \mathrm{p}}$ & $\mathrm{M}>\mathrm{D}$ & $35.8^{\mathrm{a}}, 51.8^{\mathrm{p}}$ \\
\hline (6) & H1-L20 & M & $58.2^{\mathrm{p}}$ & M & $36.4^{\mathrm{a}}, 50.4^{\mathrm{p}}$ \\
\hline (7) & $\mathrm{H} 2-\mathrm{U} 38 \mathrm{~B}$ & $\mathrm{M}<\mathrm{D}$ & $59.5^{\mathrm{p}}, 96.5^{\mathrm{p}}$ & M & $55.3^{\mathrm{p}}$ \\
\hline (8) & H2-J0 & $\mathrm{M}, \mathrm{H} \ll \mathrm{D}$ & $51.8^{\mathrm{p}}, 87.0^{\mathrm{p}}$ & $\mathrm{M}, \mathrm{H} \ll \mathrm{D}$ & $50.8^{p}$ \\
\hline (9) & H2-M15B & $\mathrm{M}$ & $46.5^{p}$ & $\mathrm{M}^{\# \&} \gg \mathrm{D}$ & $44.2^{\mathrm{p}}$ \\
\hline$(10)$ & S-M30 & $\mathrm{M}$ & $67.8^{\mathrm{a}, \mathrm{p}}$ & M & $49.6^{\mathrm{a}, \mathrm{p}}$ \\
\hline (11) & S-JX & $\mathrm{M}, \mathrm{D}^{\#}$ & $54.2^{\mathrm{a}}, 79.5^{\mathrm{p}}$ & $\mathrm{M}, \mathrm{D}$ & $35.0^{\mathrm{a}}, 39.2^{\mathrm{p}}$ \\
\hline$(12)$ & H1-JN & $\mathrm{M}$ & $48.5^{\mathrm{a}}, 46.5^{\mathrm{p}}$ & $\mathrm{M}>\mathrm{D}$ & $38.7^{\mathrm{a}}, 43.7^{\mathrm{p}}$ \\
\hline (13) & H1-K02 & $\mathrm{M}$ & $48.4^{\mathrm{a}}$ & $\mathrm{M}>\mathrm{D}$ & $32.1^{\mathrm{p}}$ \\
\hline$(14)$ & H1-M27 & $\mathrm{M}$ & $39.6^{\mathrm{a}}$ & $\mathrm{M}$ & ND \\
\hline (15) & H1-K03 & $\mathrm{D}, \mathrm{H}^{\#}$ & $60.3^{\mathrm{p}},<98^{\mathrm{p}}$ & $M^{\&}, D$ & $39.7^{\mathrm{p}}$ \\
\hline$(16)$ & H1-JN-A & M & $58.6^{\mathrm{a}, \mathrm{p}}$ & $\mathrm{D} \gg \mathrm{M}^{\# \&}$ & $37.2^{\mathrm{p}}$ \\
\hline
\end{tabular}

${ }^{\#}$ Smear represents flexible conformers; ${ }^{\text {\& }}$ the mobility can correspond to unfolded structure; M: monomer; D: dimer; H: high ordered multimer; ${ }^{\mathrm{p}}$ melting curve was obtained at $\sim 264 \mathrm{~nm}$; ${ }^{\text {a }}$ melting curve was obtained at $\sim 293 \mathrm{~nm}$. The error in $T_{m}$ determination is $\pm 3^{\circ} \mathrm{C}$.

(Figure 6). DNA oligomers $\mathrm{d}(\mathrm{AC})_{9}, \mathrm{~d}(\mathrm{AC})_{14}$, and $\mathrm{d}(\mathrm{AC})_{18}$ were used as molecular standards. Under identical conditions to those used in spectral measurements, most sequences were found to form exclusively intramolecular structures in the presence of potassium ions (Figure 6(a)). These forms move faster than the molecular standard representing the unfolded ssDNA. However, in the presence of sodium ions, smaller populations of dimeric forms are typically identified (Figure 6(b)). Dimeric structures in the presence of potassium were also observed for H2-U38, H2-U38B, H2-J0, and H1-K03. The results are summarized in Table 1.

Interestingly, the fastest band of $\mathrm{H} 1-\mathrm{K} 03$ represents a dimeric conformer, while the slowest and middle bands correspond to high-ordered structures. Preliminary NMR data indicates that $\mathrm{H} 1-\mathrm{K} 03$ forms an interlocked Gquadruplex structure which is analogical to HIV integrase aptamer [41]. The smearing of the middle band can be attributed to the presence of conformers with similar thermodynamic stabilities which possibly form one or more states during electrophoretic separation. The mobility of the dimer form of $\mathrm{H} 2-\mathrm{M} 15 \mathrm{~B}$ in the presence of sodium corresponds to the mobility of the unstructured molecular standards; therefore it is not possible to determine whether this form is a folded dimer or an unfolded dimer based on the electrophoretic record alone. However, the CD melting curve is clearly defined; this is possible only when the unknown 
structure transitions from one state to another; therefore it is possible to conclude that this band should represent a dimer structure (see Supporting Information, Figure S1).

It is important to note here, however, that not each band in a certain electrophoretic column necessarily represents a G-quadruplex structure.

3.4. TDS Analysis. The profiles of thermal difference spectra (TDS) of G-quadruplexes are highly specific, and therefore this analysis was also performed on the studied oligonucleotides, although, as our previous studies have noted, this technique is not wholly reliable and may provide erroneous results $[34,44]$. The results are summarized in Supporting Figure S2 and in Table 1. The TDS results for H2-J0, H2-U38B, and $\mathrm{H} 2-\mathrm{M} 15 \mathrm{~B}$ were somewhat ambiguous but indicated the possible formation of G-quadruplexes in the presence of both sodium and potassium ions. Interestingly, their TDS show a maximum close to $260 \mathrm{mM}$ in the presence of sodium, while the local minimum at $295 \mathrm{~nm}$ is not obvious in the presence of both sodium and potassium. Other oligonucleotides show a local minimum at $295 \mathrm{~nm}$ in TDS; for more information, see Supporting Figure S2.

More reliable results can, however, be obtained from melting curve analysis. The methodology of this technique is based on the fact that all known G-quadruplexes are more stable in the presence of potassium than in the presence of sodium ions [45]. The results of the melting curve analysis for our set of oligonucleotides revealed that the same sequences which offered interesting results in TDS assay, H2-J0, H2$\mathrm{U} 38 \mathrm{~B}$, and $\mathrm{H} 2-\mathrm{M} 15 \mathrm{~B}$, also shared intriguing features in their melting curve profiles. Each of these sequences showed identical melting temperatures regardless of whether sodium or potassium ions were present in the used buffer. This raises the unanswered question of what type of secondary structure is formed within this set of oligonucleotides. A recent study described a novel tetrahelical structural motif which is distinct from the typical G-quadruplex structure, but this form has similar spectral properties as we observed in our experiments for these three oligonucleotides [46]. This study analyzed $\mathrm{G}_{3} \mathrm{AGCG}$ repeats found in the regulatory region of the PLEKHG3 gene and found that the VK sequences $\mathrm{d}\left(\mathrm{G}_{3} \mathrm{AGCGA}\right)_{n} \mathrm{G}_{3} \mathrm{AGCG}$, where $n=1,3$, are capable of forming tetrahelical DNA stabilized with unusual noncanonical base-pairings: G-G and G-A. In addition, the sequences HPV25 and HPV25/2 found in the E4 gene of human papillomavirus type 25 also share many similar signatures [15]. These sequences prefer to adopt another fold as a G-quadruplex. Based on these findings, we decided to perform a sequence alignment of HPV25, HPV25/1, H2-M15B, H2-J0, and H2$38 \mathrm{~B}$ to assess the homology of the three sequences. The results show a relative high homology among the sequences, which indicates that these three HIV-2 sequences (H2-J0, H2-U38B, and $\mathrm{H} 2-\mathrm{M} 15 \mathrm{~B}$ ) could form structures very close to those of the HPV25 sequence (see Supporting Table S2). The melting temperatures of VK and HPV25 sequences were not dependent on the type of metal cation $[15,46]$. Extrapolating from this, it is possible to suggest that the structure may form a hairpin-like structure containing unusual G-G and G-A basepairs as was confirmed in VK. In principle, the tetrahelical
VK structure is a special case of crossed hairpin structure. It has been shown that polyethylene glycol 200 (PEG200) stabilizes G-quadruplexes in the presence of potassium and destabilizes double helical motifs [45]. However, PEG-200 significantly increases the melting temperatures of the $\mathrm{H} 2$ M15B, H2-J0, H2-38B, VK, and HPV25 sequences in the presence of potassium; see Supporting Figure S5. In order to solve this Gordian knot and determine whether the H2M15B and H2-38B sequences adopt G-quadruplex or other structural motifs, we decided to use another experimental method.

3.5. CD Titration Analysis. Recently, a newly developed experimental methodology using the ligand Thiazole Orange (TO) for the identification of G-quadruplex forming sequences has been applied [47]. TO has a strong binding affinity to triplexes and G-quadruplexes, an affinity which is significantly higher to them than to other structural motifs $[48,49]$. Although TO is optically inactive, TO-quadruplex complexes are chiral and display a unique profile of the induced CD (ICD) spectrum in the visible region [47]. This methodology offers valuable results in a wide range of conditions, but it is most sensitive in solutions without the presence of metal cations. Similarly, it can also be applied with slightly reduced sensitivity in solutions containing $\mathrm{Na}^{+}$ or low concentrations of $\mathrm{K}^{+}(<5 \mathrm{mM})$. Nevertheless, we performed the titration experiments in the presence of both $50 \mathrm{mM} \mathrm{KCl}$ and $50 \mathrm{mM} \mathrm{NaCl}$ because these concentrations of salts are more biologically relevant. The representative results of the titration analysis of $\mathrm{H1}-\mathrm{JN}$ with $\mathrm{TO}$ in the presence of $50 \mathrm{mM} \mathrm{NaCl}$ and $\mathrm{KCl}$ are shown in Figure 7.

The ICD results display the expected positive signals at $\sim 495$ and $\sim 510 \mathrm{~nm}$ and the negative signals at $\sim 475 \mathrm{~nm}$. These signatures are characteristic for TO-quadruplexes complexes [47]. The titration of all sequences is shown in Supporting Figures S3 and S4.

As expected, each oligonucleotide was also found to have formed G-quadruplexes under the given conditions. Signals corresponding to those of G-quadruplex structures were also clearly detected in the UV region. In case of antiparallel G-quadruplexes, the signals at 295 and $265 \mathrm{~nm}$ were seen to decrease and increase, respectively, by increasing the concentration of TO, phenomena which are indicative of the conversion from antiparallel to parallel folding.

The titration analysis of the HPV25 sequence shows that ICD was mirrored; the positive peaks become negative and vice versa. It is therefore possible to assume that the binding mode of TO with this sequence must be different than those typical for G-quadruplex motifs (Figure 8). The same effect was also observed for VK sequence. These results indicate that $\mathrm{H} 2-\mathrm{M} 15 \mathrm{~B}, \mathrm{H} 2 \mathrm{~J} 0$, and $\mathrm{H} 2-\mathrm{U} 38 \mathrm{~B}$ are also able to form Gquadruplex structures.

\section{Conclusion}

Our bioinformatic study of HIV genomes partially corresponds with the analyses recently published by many authors in that it too focuses primarily on G-rich regions located in U3 LTRs. However, this study reveals that G-quadruplexes 


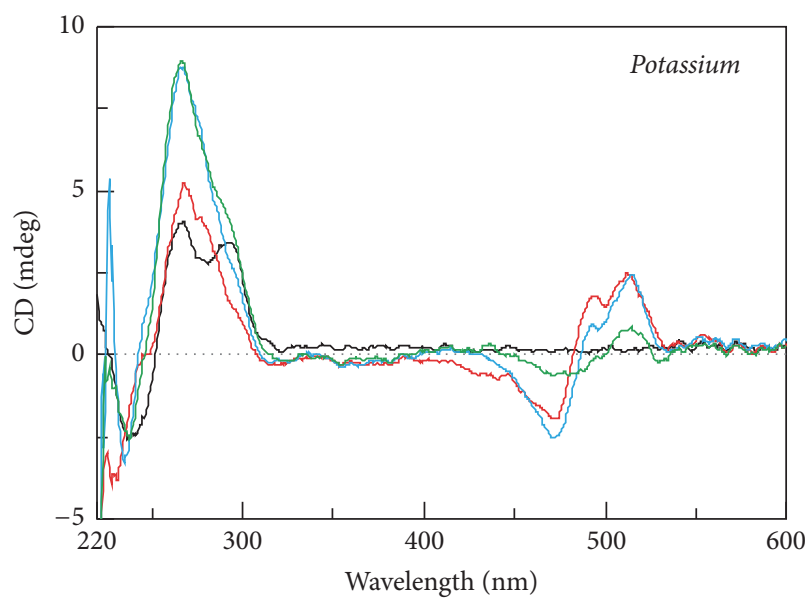

(a)

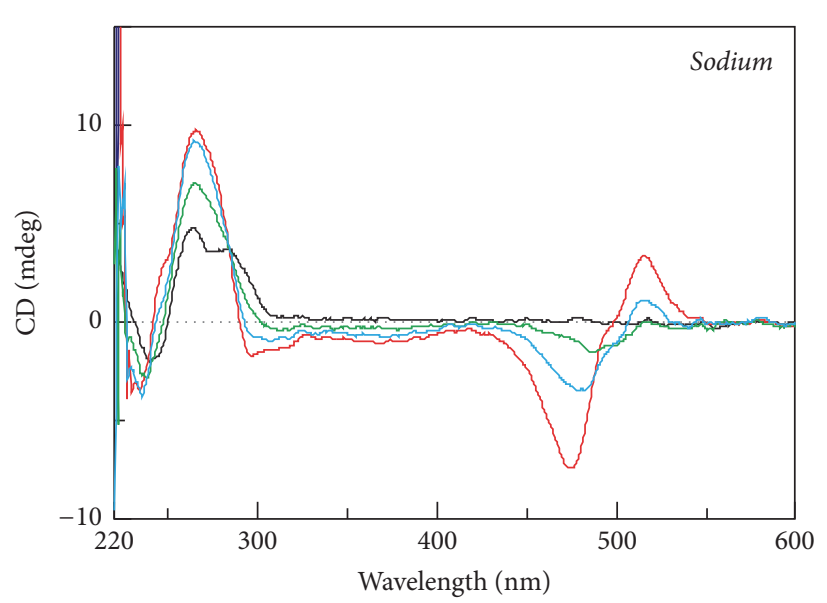

(b)

FIGURE 7: The representative CD titration spectra of $\sim 27 \mu \mathrm{M}$ H1-JN with TO. 0, 2.5, 5, and 7.5 molar equivalents of TO represent black, green, blue, and red lines, respectively. Each sample was measured in modified $25 \mathrm{mM}$ Britton-Robinson containing (a) $50 \mathrm{mM} \mathrm{KCl}$ and (b) $50 \mathrm{mM}$ $\mathrm{KCl}$.

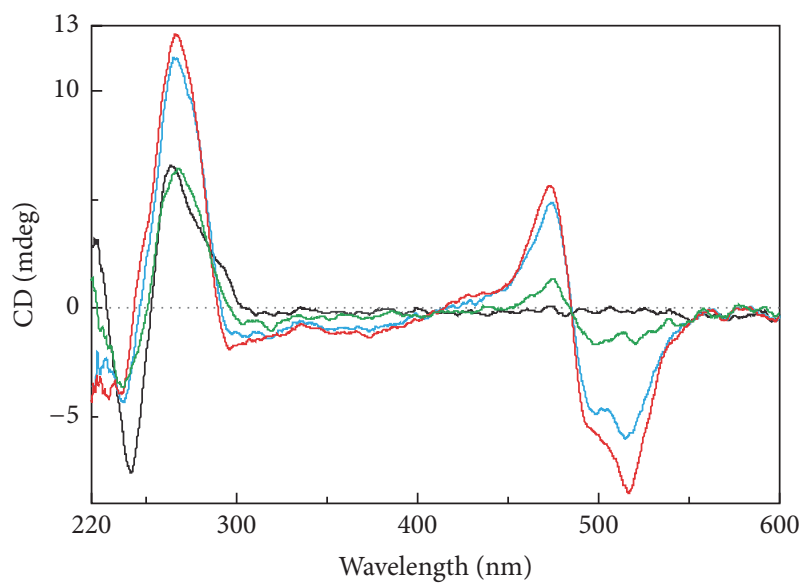

Figure 8: CD titration spectra of $27 \mu \mathrm{M}$ HPV25/1 (d(GGGAGCGGGAC-TGGGACCGGGACCG-GG)) with TO. 0, 2.5, 5, and 7.5 molar equivalents of TO are represented by black, green, brown, and red lines, respectively. Each sample was measured in a modified $25 \mathrm{mM} \mathrm{mBR}$ buffer containing $50 \mathrm{mM} \mathrm{NaCl}$.

can be formed in HIV provirus DNA when it only consists of three G-runs and one $G_{2}$. These domains are not necessarily located only in regulating LTRs, but also in other gene coding regions. In addition, G-rich domains were also located in the minus-strand of many HIV-1 isolates, the sequence of which is highly homological with the well-known sequence forming the interlocked and extremely stable HIV integrase aptamer [41].

Several unanswered questions require deeper analysis to determine the features that provide specific G-quadruplex motifs with the ability to function as structural elements.

In this study, we used only the cost-effective methods to confirm that some oligonucleotides form G-quadruplex motifs. However, we again demonstrate that ICD signal of TO-quadruplex complex offers valuable additional information, allowing distinguishing whether an unknown sequence has ability to adopt G-quadruplex structure.

\section{Conflicts of Interest}

The authors declare that they have no conflicts of interest.

\section{Acknowledgments}

This work was supported by the Slovak Research and Development Agency under Contract no. APVV-0280-11, European Cooperation in Science and Technology (COST CM1406), Slovak Grant Agency 1/0131/16, and internal university grants (VVGS-PF-2017-251 and VVGS-2016-2596). The authors thank G. Cowper for critical reading and correction of the manuscript.

\section{Supplementary Materials}

Table S1: the sequence alignment of the regions determined by NF- $\kappa-\mathrm{B}$ and TATA boxes located in LTRs containing the sequences used in this study. Table $S 2$ : sequence alignments of HPV25, HPV25/1, H2-M15B, H2-J0, and H2-38B. Figure S1: the condition of $\mathrm{CD}$ spectra and melting curve measurements are the same as in Figure 3. Measurements in the presence of $50 \mathrm{mM} \mathrm{NaCl}$ and $50 \mathrm{mM} \mathrm{KCl}$ are represented as blue and black lines, respectively. The melting curves were obtained at $265 \mathrm{~nm}$ (solid lines) and $294 \mathrm{~nm}$ (dotted lines). The relative $\mathrm{CD}$ intensity is compared with the reference HTR oligonucleotide $d(G 3 T 2 A) 3 G 3$. The value of 1 is obtained when the molar CD signal at $295 \mathrm{~nm}$ is the same as the CD signal of HTR at the same concentration [Tóthová et al. Biochemistry 53, 2014, 7013-27]. Figure S2: thermal difference spectra in the presence of sodium (blue lines) and potassium (black lines). Figure S3: the CD titration spectra of $27 \mu \mathrm{M}$ DNA sample with TO; $0,2.5,5$, and 7.5 molar equivalents of TO are represented by black, green, blue, 
and red lines, respectively. Each sample was measured in a modified $25 \mathrm{mM}$ mBR buffer containing $50 \mathrm{mM} \mathrm{NaCl}$. Figure S4: CD titration spectra of $27 \mu \mathrm{M}$ DNA sample with TO. 0 , 2.5, 5, and 7.5 molar equivalents of TO are represented by black, green, blue, and red lines, respectively. Each sample was measured in a modified $25 \mathrm{mM} \mathrm{mBR}$ buffer containing $50 \mathrm{mM} \mathrm{KCl}$. Figure S5: CD spectra and melting curves of H2$\mathrm{M} 15 \mathrm{~B}, \mathrm{VK}$, and HPV25/1 sequences in $50 \mathrm{mM} \mathrm{KCl}$ and the presence (magenta) and absence of 50\% v/w PEG200 (black lines). (Supplementary Materials)

\section{References}

[1] M. Metifiot, S. Amrane, S. Litvak, and M.-L. Andreola, "Survey and summary G-quadruplexes in viruses: Function and potential therapeutic applications," Nucleic Acids Research, vol. 42, no. 20, pp. 12352-12366, 2014.

[2] E. Tosoni, I. Frasson, M. Scalabrin et al., "Nucleolin stabilizes Gquadruplex structures folded by the LTR promoter and silences HIV-1 viral transcription," Nucleic Acids Research, vol. 43, no. 18, pp. 8884-8897, 2015.

[3] D. Piekna-Przybylska, M. A. Sullivan, G. Sharma, and R. A. Bambara, "U3 region in the HIV-1 genome adopts a Gquadruplex structure in its RNA and DNA sequence," Biochemistry, vol. 53, no. 16, pp. 2581-2593, 2014.

[4] S. Amrane, A. Kerkour, A. Bedrat, B. Vialet, M.-L. Andreola, and J.-L. Mergny, "Topology of a DNA G-quadruplex structure formed in the HIV-1 promoter: a potential target for anti-HIV drug development," Journal of the American Chemical Society, vol. 136, no. 14, pp. 5249-5252, 2014.

[5] R. Perrone, M. Nadai, J. A. Poe et al., "Formation of a unique cluster of G-quadruplex structures in the HIV-1 nef coding region: implications for antiviral activity," PLoS ONE, vol. 8, no. 8, Article ID e73121, 2013.

[6] R. Perrone, M. Nadai, I. Frasson et al., "A dynamic Gquadruplex region regulates the HIV-1 long terminal repeat promoter," Journal of Medicinal Chemistry, vol. 56, no. 16, pp. 6521-6530, 2013.

[7] R. Perrone, E. Lavezzo, G. Palù, and S. N. Richter, "Conserved presence of G-quadruplex forming sequences in the long terminal repeat promoter of Lentiviruses," Scientific Reports, vol. 7, no. 1, 2017.

[8] M. Düchler, "G-quadruplexes: Targets and tools in anticancer drug design," Journal of Drug Targeting, vol. 20, no. 5, pp. 389400, 2012.

[9] D. J. Patel, A. T. Phan, and V. Kuryavyi, "Human telomere, oncogenic promoter and 5/-UTR G-quadruplexes: diverse higher order DNA and RNA targets for cancer therapeutics," Nucleic Acids Research, vol. 35, no. 22, pp. 7429-7455, 2007.

[10] S. Balasubramanian, L. H. Hurley, and S. Neidle, "Targeting Gquadruplexes in gene promoters: A novel anticancer strategy?" Nature Reviews Drug Discovery, vol. 10, no. 4, pp. 261-275, 2011.

[11] A. Siddiqui-Jain, C. L. Grand, D. J. Bearss, and L. H. Hurley, "Direct evidence for a G-quadruplex in a promoter region and its targeting with a small molecule to repress c-MYC transcription," Proceedings of the National Acadamy of Sciences of the United States of America, vol. 99, no. 18, pp. 11593-11598, 2002.

[12] J. Norseen, F. B. Johnson, and P. M. Lieberman, "Role for Gquadruplex RNA binding by Epstein-Barr virus nuclear antigen
1 in DNA replication and metaphase chromosome attachment," Journal of Virology, vol. 83, no. 20, pp. 10336-10346, 2009.

[13] P. Murat, J. Zhong, L. Lekieffre et al., "G-quadruplexes regulate Epstein-Barr virus-encoded nuclear antigen 1 mRNA translation," Nature Chemical Biology, vol. 10, no. 5, pp. 358-364, 2014.

[14] S. Wang, Y. Min, J. Wang et al., "A highly conserved G-rich consensus sequence in hepatitis $\mathrm{C}$ virus core gene represents a new anti-hepatitis C target," Science Advances, vol. 2, no. 4, Article ID e1501535, 2016.

[15] K. Tlučková, M. Marušič, P. Tóthová et al., "Human papillomavirus G-quadruplexes," Biochemistry, vol. 52, no. 41, pp. 7207-7216, 2013.

[16] D. Piekna-Przybylska, G. Sharma, and R. A. Bambara, "Mechanism of HIV-1 RNA dimerization in the central region of the genome and significance for viral evolution," The Journal of Biological Chemistry, vol. 288, no. 33, pp. 24140-24150, 2013.

[17] N. Jouvenet, S. Lainé, L. P. Vivares, and M. Mougel, "Cell biology of retroviral RNA packaging," RNA Biology, vol. 8, no. 4, 2011.

[18] W.-S. Hu and H. M. Temin, "Retroviral recombination and reverse transcription," Science, vol. 250, no. 4985, pp. 1227-1233, 1990.

[19] C. Charpentier, T. Nora, O. Tenaillon, F. Clavel, and A. J. Hance, "Extensive recombination among human immunodeficiency virus type 1 quasispecies makes an important contribution to viral diversity in individual patients," Journal of Virology, vol. 80, no. 5, pp. 2472-2482, 2006.

[20] W. I. Sundquist and S. Heaphy, "Evidence for interstrand quadruplex formation in the dimerization of human immunodeficiency virus 1 genomic RNA," Proceedings of the National Acadamy of Sciences of the United States of America, vol. 90, no. 8, pp. 3393-3397, 1993.

[21] G. Awang and D. Sen, "Mode of dimerization of HIV-1 genomic RNA," Biochemistry, vol. 32, no. 42, pp. 11453-11457, 1993.

[22] R. Marquet, J.-C. Paillart, E. Skripkin, C. Ehresmann, and B. Ehresmann, "Dimerization of human immunodeficiency virus type 1 RNA involves sequences located upstream of the splice donor site," Nucleic Acids Research, vol. 22, no. 2, pp. 145-151, 1994.

[23] W. Shen, R. J. Gorelick, and R. A. Bambara, "HIV-1 nucleocapsid protein increases strand transfer recombination by promoting dimeric G-quartet formation," The Journal of Biological Chemistry, vol. 286, no. 34, pp. 29838-29847, 2011.

[24] S. G. Hershman, Q. Chen, J. Y. Lee et al., "Genomic distribution and functional analyses of potential G-quadruplex-forming sequences in Saccharomyces cerevisiae," Nucleic Acids Research, vol. 36, no. 1, pp. 144-156, 2008.

[25] A. Bedrat, L. Lacroix, and J.-L. Mergny, "Re-evaluation of Gquadruplex propensity with G4Hunter," Nucleic Acids Research, vol. 44, no. 4, pp. 1746-1759, 2016.

[26] M. Yano and Y. Kato, "Using hidden Markov models to investigate G-quadruplex motifs in genomic sequences," BMC Genomics, vol. 15, article no. S15, 2014.

[27] P. Dhapola and S. Chowdhury, "QuadBase2: web server for multiplexed guanine quadruplex mining and visualization," Nucleic Acids Research, vol. 44, no. W1, pp. W277-W283, 2016.

[28] J. L. Huppert and S. Balasubramanian, "Prevalence of quadruplexes in the human genome," Nucleic Acids Research, vol. 33, no. 9, pp. 2908-2916, 2005.

[29] A. K. Todd, M. Johnston, and S. Neidle, "Highly prevalent putative quadruplex sequence motifs in human DNA," Nucleic Acids Research, vol. 33, no. 9, pp. 2901-2907, 2005. 
[30] M. Marušič, R. N. Veedu, J. Wengel, and J. Plavec, "G-rich VEGF aptamer with locked and unlocked nucleic acid modifications exhibits a unique G-quadruplex fold," Nucleic Acids Research, vol. 41, no. 20, pp. 9524-9536, 2013.

[31] V. T. Mukundan and A. T. Phan, "Bulges in G-quadruplexes: Broadening the definition of G-quadruplex-forming sequences," Journal of the American Chemical Society, vol. 135, no. 13, pp. 5017-5028, 2013.

[32] O. Kikin, L. D’Antonio, and P. S. Bagga, "QGRS Mapper: a web-based server for predicting G-quadruplexes in nucleotide sequences," Nucleic Acids Research, vol. 34, pp. W676-W682, 2006.

[33] S. F. Altschul, T. L. Madden, A. A. Schäffer et al., "Gapped BLAST and PSI-BLAST: a new generation of protein database search programs," Nucleic Acids Research, vol. 25, no. 17, pp. 3389-3402, 1997.

[34] P. Tóthová, P. Krafćíková, and V. Víglaský, "Formation of highly ordered multimers in G-quadruplexes," Biochemistry, vol. 53, no. 45, pp. 7013-7027, 2014.

[35] B. J. Bassam and P. M. Gresshoff, "Silver staining dna in polyacrylamide gels," Nature Protocols, vol. 2, no. 11, pp. 26492654, 2007.

[36] I. Kejnovská, K. Bednářová, D. Renčiuk et al., "Clustered abasic lesions profoundly change the structure and stability of human telomeric G-quadruplexes," Nucleic Acids Research, vol. 45, no. 8, pp. 4294-4305, 2017.

[37] B. Heddi, N. Martín-Pintado, Z. Serimbetov, T. M. A. Kari, and A. T. Phan, "G-quadruplexes with $(4 n-1)$ guanines in the G-tetrad core: Formation of a G-triad-water complex and implication for small-molecule binding," Nucleic Acids Research, vol. 44, no. 2, pp. 910-916, 2016.

[38] S. L. Wolin and P. Walter, "Ribosome pausing and stacking during translation of a eukaryotic mRNA.," EMBO Journal, vol. 7, no. 11, pp. 3559-3569, 1988.

[39] L. J. Core, J. J. Waterfall, D. A. Gilchrist et al., "Defining the Status of RNA Polymerase at Promoters," Cell Reports, vol. 2, no. 4, pp. 1025-1035, 2012.

[40] A. Madireddy, P. Purushothaman, C. P. Loosbroock, E. S. Robertson, C. L. Schildkraut, and S. C. Verma, "G-quadruplexinteracting compounds alter latent DNA replication and episomal persistence of KSHV,' Nucleic Acids Research, vol. 44, no. 8, pp. 3675-3694, 2016.

[41] A. T. Phan, V. Kuryavyi, J.-B. Ma, A. Faure, M.-L. Andréola, and D. J. Patel, "An interlocked dimeric parallel-stranded DNA quadruplex: a potent inhibitor of HIV-1 integrase," Proceedings of the National Acadamy of Sciences of the United States of America, vol. 102, no. 3, pp. 634-639, 2005.

[42] B. De Nicola, C. J. Lech, B. Heddi et al., "Structure and possible function of a G-quadruplex in the long terminal repeat of the proviral HIV-1 genome," Nucleic Acids Research, vol. 44, no. 13, pp. 6442-6451, 2016.

[43] V. Víglaský, K. Tlučková, and L'. Bauer, “The first derivative of a function of circular dichroism spectra: Biophysical study of human telomeric G-quadruplex," European Biophysics Journal, vol. 40, no. 1, pp. 29-37, 2011.

[44] J.-L. Mergny, J. Li, L. Lacroix, S. Amrane, and J. B. Chaires, "Thermal difference spectra: a specific signature for nucleic acid structures," Nucleic Acids Research, vol. 33, no. 16, p. el38, 2005.

[45] D. Miyoshi, A. Nakao, and N. Sugimoto, "Molecular crowding regulates the structural switch of the DNA G-quadruplex," Biochemistry, vol. 41, no. 50, pp. 15017-15024, 2002.
[46] V. Kocman and J. Plavec, "A tetrahelical DNA fold adopted by tandem repeats of alternating GGG and GCG tracts," Nature Communications, vol. 5, article no. 6831, 2014.

[47] P. Krafč́́ková, E. Demkovičová, and V. Víglaský, "Ebola virus derived G-quadruplexes: Thiazole orange interaction," Biochimica et Biophysica Acta (BBA) - General Subjects, vol. 1861, no. 5, pp. 1321-1328, 2016.

[48] I. Lubitz, D. Zikich, and A. Kotlyar, "Specific high-affinity binding of thiazole orange to triplex and g-quadruplex DNA," Biochemistry, vol. 49, no. 17, pp. 3567-3574, 2010.

[49] J. Mohanty, N. Barooah, V. Dhamodharan, S. Harikrishna, P. I. Pradeepkumar, and A. C. Bhasikuttan, "Thioflavin T as an efficient inducer and selective fluorescent sensor for the human telomeric G-quadruplex DNA," Journal of the American Chemical Society, vol. 135, no. 1, pp. 367-376, 2013. 

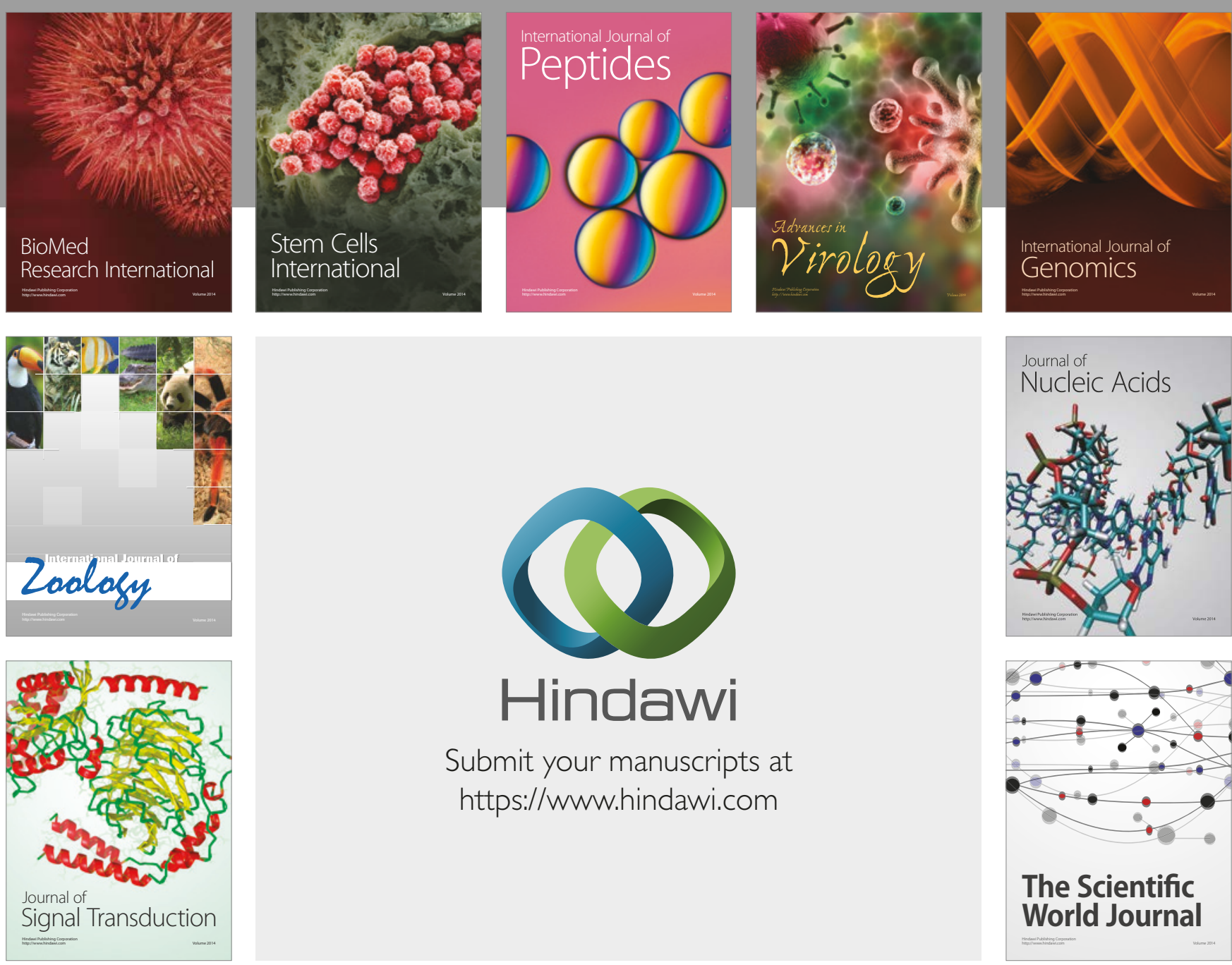

Submit your manuscripts at

https://www.hindawi.com
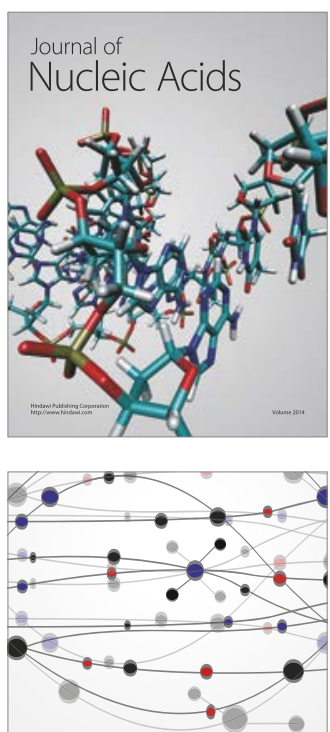

The Scientific World Journal

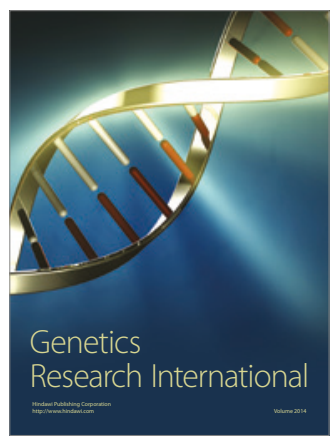

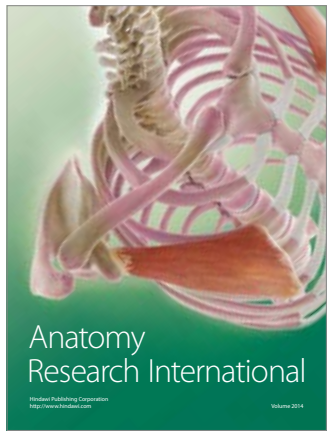

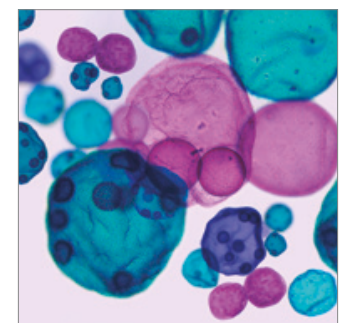

International Journal of Microbiology
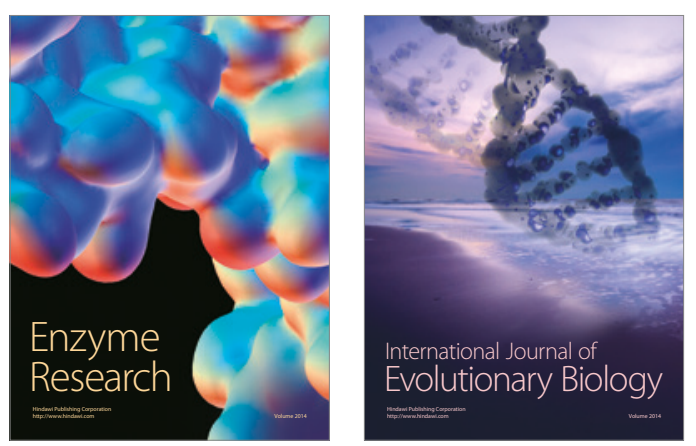
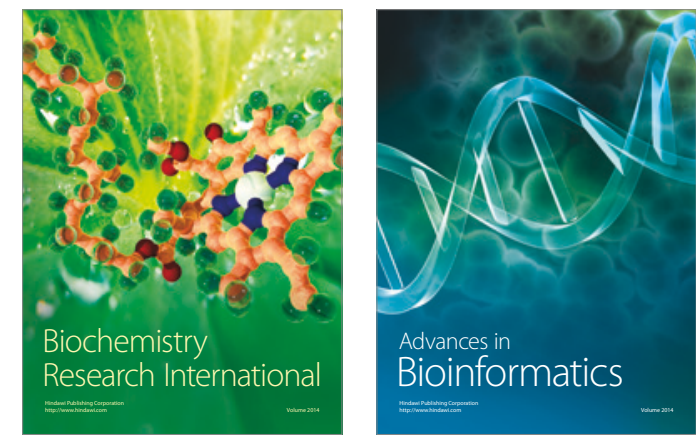

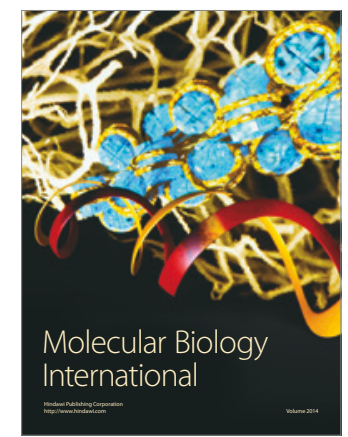

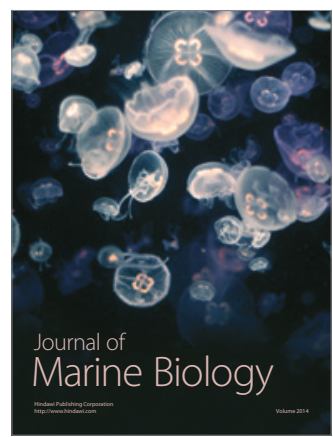

